\title{
Phosphorus Adsorption Desorption Model of River Sediment
}

\author{
Qian WANG ${ }^{1,2, a}$, Yu QIN ${ }^{1, b, *}$, Jing-Yun HUANG ${ }^{1, c}$ \\ ${ }^{1}$ Key Laboratory of Hydraulic and Waterway Engineering of Ministry of Education, Chongqing Jiao \\ Tong University, Chongqing 400000, China \\ ${ }^{2}$ Key Laboratory for Eco-Efficient Polysilicate Materials, School of Environment and Energy, Peking \\ University Shenzhen Graduate School, Guangdong 518055, China \\ awq_20140923@163.com, bqinyu54001@163.com, chuangjingyun0609@gmail.com \\ ${ }^{\star}$ Corresponding author
}

Keywords: Suspended Load Sediment, Phosphorus, Adsorption-Desorption Effect, Open Channel Model.

\begin{abstract}
Phosphorus adsorption and desorption in natural waters have played a crucial role in the ecology of rivers and reservoirs. Hence, the purpose of this work was used to study the effect of sediment's characteristics on phosphorus adsorption and desorption. The experiment uses open channel model, instead of conventional shaking flask. The phosphorus concentration of water will be periodically sampled and analyzed. Secondary dynamics equation and Elovich equation were used to stimulate the process. The results showed that shorter balance time attribute to smaller particle size and higher sediment's concentration. Finally, the influence of different equation on phosphorus adsorption stimulation would discuss in this work.
\end{abstract}

\section{Introduction}

Phosphorus was the main elements of eutrophication. 97\% of the mass transport of metals was associated with river sediments ${ }^{[1]}$. Therefore, the physical and chemical properties of sediments would affect the phosphorus adsorption-desorption. The releasing of the sediment's nutrient contributed to algae growth. Many studies showed that sediment's phosphorus concentration accelerate sediment releasing. Sediment releasing phosphorus was mainly decided by the condition of water dissolving insoluble phosphate (mainly calcium salt, aluminum salt and iron salts) ${ }^{[2,3]}$. Once qualified, sediment would begin to release phosphorus. $\mathrm{pH}$, temperature, hydrological condition of water and sediment would affect the adsorption of phosphorus.

Sediment on phosphorus adsorption was considered to be physicochemistry adsorption process. First order kinetics adsorption equation, the secondary dynamics equation, Langmuir and Elovich equation were used to describe the adsorption process. In this paper, Elovich and second order kinetic model were applied to analyze. The characteristics of these equations were as follows: in Elovich model, $\mathrm{t}$ keeps rising with no equilibrium. Second order kinetic model can calculate adsorption quantity at equilibrium.

Sediment adsorbed phosphorus mainly occurring within $1 \mathrm{~h}$. The content of fine sand significantly affected the adsorption efficiency ${ }^{[4]}$. Langmuir equation could describe the adsorption process better, adsorption equilibrium time was greatly affected by the saturated adsorption amount and sediment concentration $^{[5,6]}$. Above all, researchers have carried research mainly concentrated in the sediment of the static adsorption of phosphorus releasing. Few researchers focused on the effect of water and sediment characteristics on phosphorus adsorption. Hence, the influence of particle size and 
concentration on phosphorus was discussed in this work.

\section{Material and Methods}

\section{Experimental Sand}

According to the river sediment movement mechanics, suspended load sediments easily settled in the region of the reducing velocity flow ${ }^{[7]}$. The sand used in this experiment was derived from the reducing velocity area in jialing river huaxin street section. Before the experiment, sand was divided into four types: fine sand $(0.15 \sim 0.25 \mathrm{~mm})$, very fine sand $(0.075 \sim 0.15 \mathrm{~mm})$, silt $(0.038 \sim 0.075 \mathrm{~m})$, and silt clay $(\leq 0.038 \mathrm{~mm})$.

\section{Open Channel Model}

The open channel model was $8 \mathrm{~m}$ in length, $0.07 \mathrm{~m}$ in width. The model set large slope $(0.061)$, wide depth ratio (12.5) to obtain a higher Reynolds number (3826). Compared to the shake flask, open channel with high speed could better simulate turbulent flow in real river. Total volume of system water is $4 \mathrm{~L}$; single test sampling 22 times, a single sample wasn't more than $5 \mathrm{ml}$, single test water sampling $88 \mathrm{ml}$, accounting $2.75 \%$ of the system total water, causing low influence on system operation. Model used cyclic flow through pump power. Two order reciprocating structure sets to minimum the space between starting point and end point. The pipe length was about $0.8 \mathrm{~m}$. The connection of pipe and open channel used upstream shock to avoid sediment deposition. The malchite green-phosphorus molybdenum heteropoly acid spectrophotometric method was used to detect the content of phosphorus.

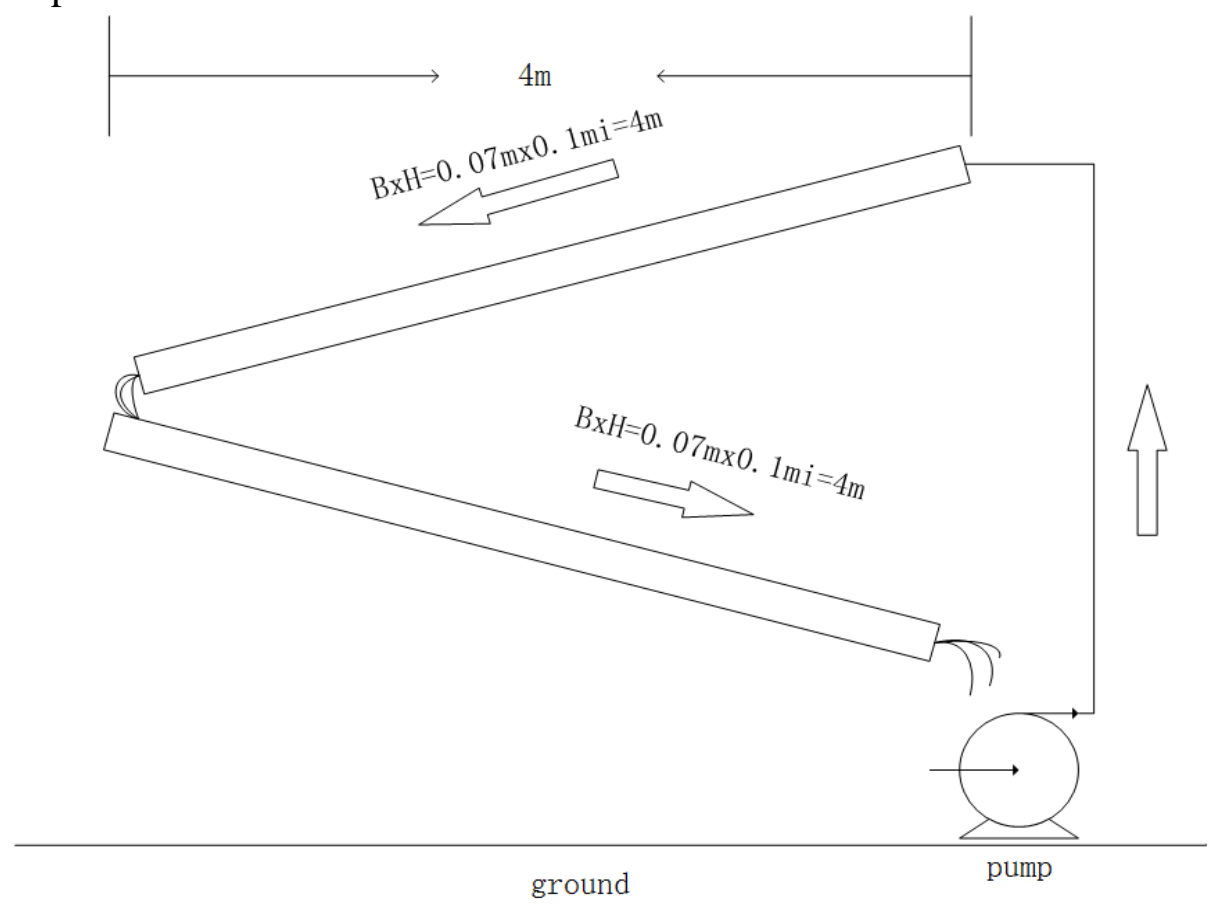

Vertical sectional drawing

Cross sectional drawing

Fig.1 Model Profile 


\section{Results and Discussion}

\section{The Effects of Different Particle Size}

The initial sediment concentration was $1.0 \mathrm{~g} / \mathrm{L}$. Four batch columns were conducted with different particle size: fine sand $(0.15 \sim 0.25 \mathrm{~mm})$, very fine sand $(0.075 \sim 0.15 \mathrm{~mm})$, silt $(0.038 \sim 0.075 \mathrm{~m})$, silt clay $(\leq 0.038 \mathrm{~mm})$. Three parallel samples were used to analyze. Each group's total test lasted for 370 minutes. Elovich equation and secondary dynamics equation are used to simulate the model. The stimulation results were presented in Fig. 3 and Fig.4.
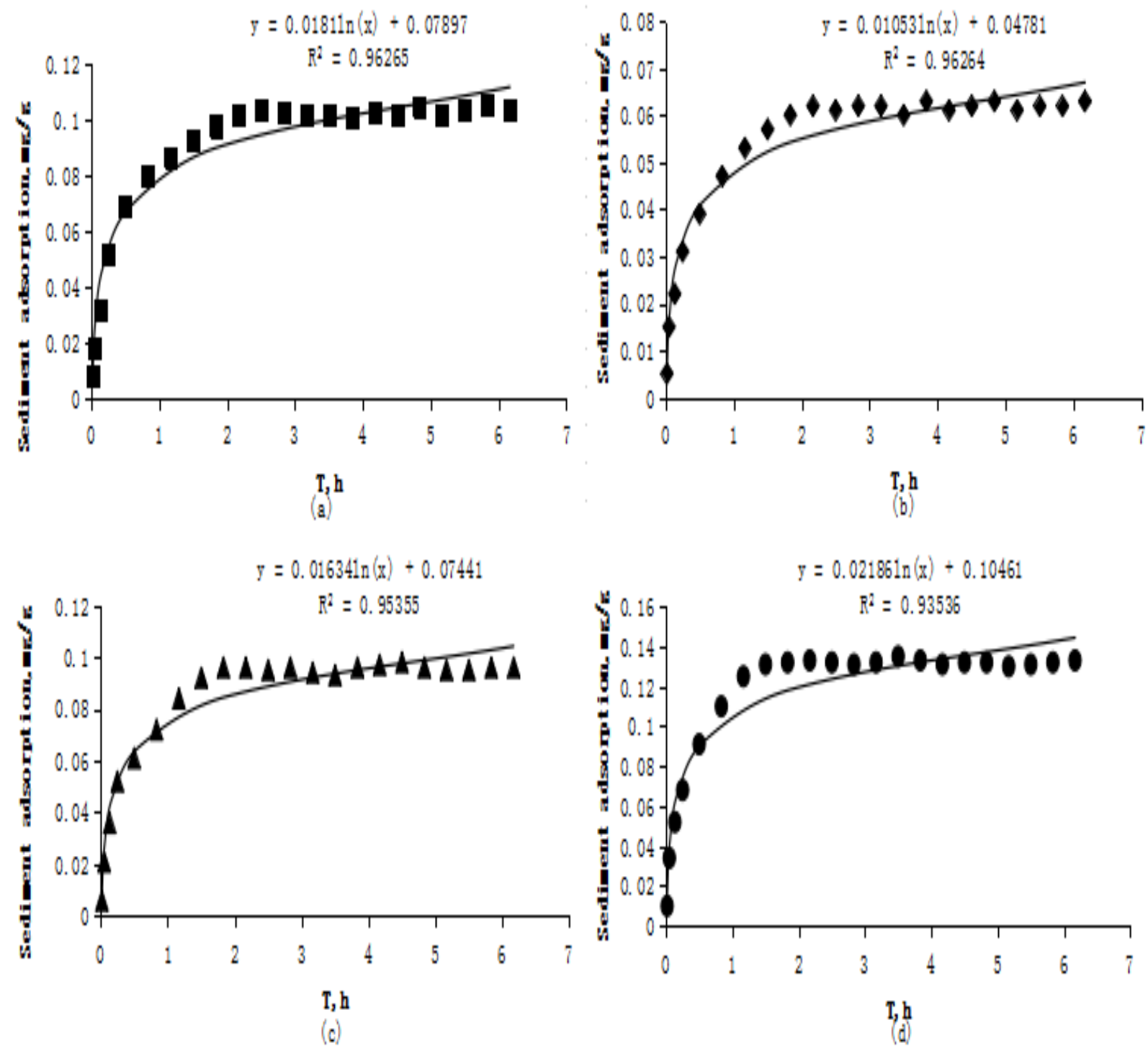

Fig.2 Different Sediments Adsorption Elovich Equation Stimulation Results, from (a) to (d) Represents: Fine Sand, Very Fine Sand, Silt, Clay Silt

It can be concluded that four types of sediment particle size on the adsorption of phosphorus process can achieve balance within $3 \mathrm{~h}$. Sediment particle size was different, the sediment adsorption capacity and equilibrium time were also different. Respectively, the balance time is: $150 \mathrm{~min}$ (fine), $120 \mathrm{~min}$ (very fine), $120 \mathrm{~min}$ (silt), $80 \mathrm{~min}$ (clay silt). The change trends of four kinds sediment were the same: first rising sharply, gradually slow, later balance. According to the results, phosphorus adsorption ability of different type sediment was in the order: clay silt $>$ fine sand $>$ silt $>$ very fine sand. 


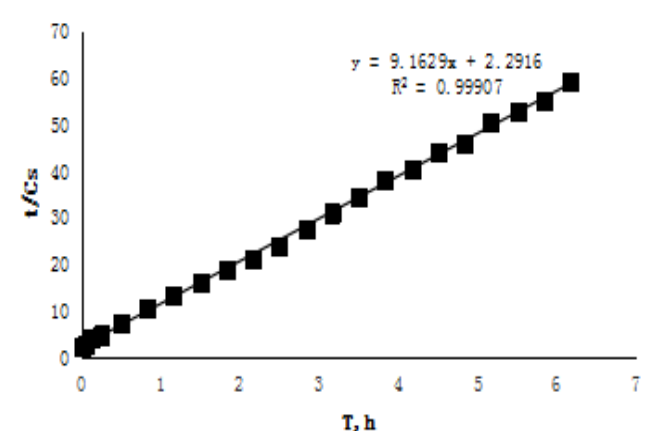

(a)



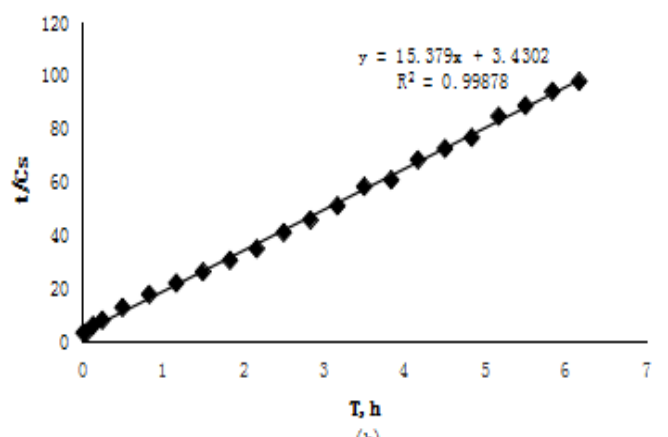

(b)

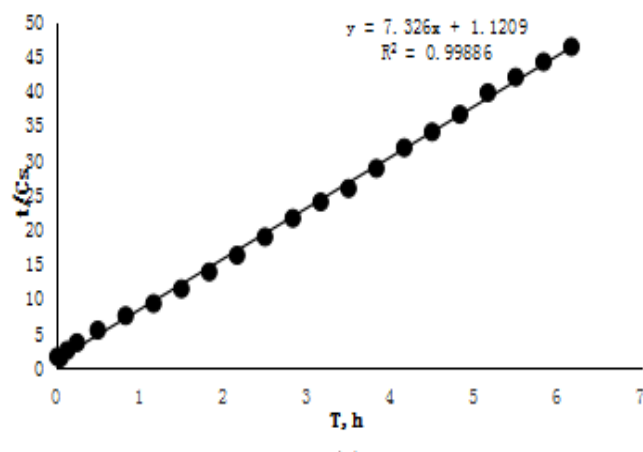

(d)

Fig.3 Different Sediments Adsorption Secondary Dynamics Equation Stimulation Results, from (a) to (d) Represents: Fine Sand, Very Fine Sand, Silt, Clay Silt

\section{The Effects of Different Stimulation Equation}

Physical adsorption was van der Wals force between adsorbent and the adsorbate molecule ${ }^{[8]}$. The adsorption was associated with the surface which brought by adsorbent. These molecules with uneven surface could unbalance gravity. There was excess free energy of the residual gravity. It was called surface energy because produced and exist on the surface. Under the circumstances of less internal pore in the sediment, the smaller particle size, the specific surface area, the more adsorption point could be provided. The comprehensive results are presented in Tab.1.

Tab1. Different Particle Size of Sediment Adsorption Test

\begin{tabular}{ccccccc}
\hline $\begin{array}{c}\text { Different } \\
\text { particle }\end{array}$ & \multicolumn{3}{c}{ Elovich model } & \multicolumn{4}{c}{ Second order kinetic model } \\
\hline $\begin{array}{c}\text { Fine sand } \\
0.15 \sim 0.25 \mathrm{~mm}\end{array}$ & 9.163 & 2.292 & 0.963 & 0.109 & 36.638 & 0.999 \\
$\begin{array}{c}\text { Very fine sand } \\
0.075 \sim 0.15 \mathrm{~mm}\end{array}$ & 15.379 & 3.430 & 0.963 & 0.065 & 68.950 & 0.999 \\
$\begin{array}{c}\text { Silt } \\
0.038 \sim 0.075 \mathrm{~mm} \\
\text { Silt clay } \\
\leq 0.038 \mathrm{~mm}\end{array}$ & 9.987 & 2.052 & 0.954 & 0.100 & 48.600 & 0.999 \\
\hline
\end{tabular}

It was obviously that the correlation coefficient of secondary dynamic equation was higher than Elovich equation in four particle size. The data deviation of Elovich equation was considerable. In the first stage, Elovich equation could achieve a good simulation effect. It couldn't stimulate data well. In contrast, the secondary dynamic equation could simulate sediment phosphorus adsorption process better. Its correlation coefficient was high and the deviation was small. At equlibrium, the phosphorus adsorption abilities were in the order:silt clay (0.135), fine sand (0.102), silt (0.095), very 
fine sand (0.06). Generally, saturated adsorption amount were not in strict accordance with the arrangement of sediment particle size order.

\section{Conclusion}

Compared with the shake flask test, open channel model can better simulate the real flow of the river. In the simulation model of open channel sediment phosphorus adsorption kinetics aspect, the stimulation result of secondary dynamics equation fit the data better. The decreasing of phosphorus in water was in accompanied with increasing sediment phosphorus adsorption. Above all, absorption rate reduced slowly after the phosphorus adsorption achieved a balance.

\section{Acknowledgement}

This research was financially supported by the open fund of Chongqing jiaotong university of water conservancy engineering key laboratory \& the national inland waterway regulation engineering technology research center(project number: SLK2012A03) and Chongqing college students' innovative entrepreneurial project(project number:20140618015).

\section{References}

[1] Gibbs, R. J, Transport Phases of Transition Metals in the Amazon and Yukon Rivers, J. Geol.Soc. Amer. Bull. 88(1977) 829-843.

[2] Chakrapau G J, Subramanian V, Fractionation of heavy metals and phosphorus in suspended sediments of the Yamuna River, India, J. Environ. Monist. Assess. 43(1996) 117-124.

[3] Xianqiang Tang, Miu Wu, Xichang Dai (eds.), Phosphorus storage dynamics and adsorption characteristics for sediment from a drinking water source reservoir and its relation with sediment compositions, J. Ecological Engineering. 64(2014) 276-284.

[4] Lopez P., Lluch X., Vidal M., Adsorption of phosphorus on sediments of the Balearic related to their composition, J. Estuarine Coastal and Shelf Science. 42(1996) 185-195.

[5] Jugsujinda A. A., Krairapanona W. H., Patrick J. R., Influence of extractable iron, aluminum, and manganese of P sorption in flooded acid sulfate soils, J. Biol. Fortil. Soil.20 (1995) 118-124.

[6] Jones R. I., Shaw P. J., Haan H. HE., Effects of dissolved humic substances on the speciation of iron and phosphate ant different pH and ionic stength, J. Environ. Sci. Technol., 27(1993) 1052-1059.

[7] Ozacar M, Equilibrium and kictic modeling of adsorption of phosphorus on calcined alunite, J. Adsorpution, 9(2003) 125.

[8] Scheufele, Fabiano Bisinella Módenes, Aparecido NivaldoBorba et al., Monolayer multilayer adsorption phenomenological model: Kinetics, equilibrium and thermodynamics, J. Chemical Engineering Journal, 284(2016) 1328-1341. 